\title{
Formação Moral e Ética nos Cursos de Graduação
}

\author{
Caio César Coelho Rodrigues ${ }^{1}$, Ricardo Leite Camargo ${ }^{2}$ \\ ${ }^{1}$ Escola de Administração e Economia de São Paulo da Fundação Getúlio Vargas \\ 2Escola Superior de Agricultura "Luiz de Queiroz" da Universidade de São Paulo \\ * Autores para correspondência: caio.coelho.rodrigues@gmail.com; ricardocamargo@usp.br
} GradF

Revista de Graduação USP

\section{RESUMO}

Baseado nos conceitos de La Taille (2006) em que a ética contempla a moral, mas também envolve o projeto de vida e a trajetória profissional, o presente estudo buscou analisar as reflexões sobre o sucesso profissional dentro de um curso de graduação em Administração. Investigando o projeto de vida, as concepções da universidade sobre o sucesso profissional e seus desdobramentos, descobriu-se que os alunos podem ou não incluir a preocupação com o outro na sua visão de sucesso profissional, mas eles entendem a necessidade de um esforço tanto da instituição como do corpo discente para realizar essa discussão no âmbito universitário.

Palavras-Chave: Moral; Ética; Educação; Universidade.

\begin{abstract}
Based on the concepts of La Taille (2006) in which ethics includes moral, but also involves the design of life and the professional trajectory, this study sought to analyze the reflections on professional success within an undergraduate business course. Investigating the life project, the views of the university on professional success and its consequences. It was discovered that students may or may not include concern for others in their professional vision of success, but they understand the need for an effort of both the institution and the student body to conduct this discussion in the University.
\end{abstract}

Keywords: Moral; Ethics; Education; University.

\section{Introdução}

Um assunto que chama a atenção e que abrange toda e qualquer área do conhecimento é a moral, palavra essa que sempre está acompanhada de sua irmã, a ética. Aquela, originada do latim, era associada aos costumes, e esta, de origem grega, era primordialmente associada ao modo de vida ou ao caráter. Ambas têm a sua semelhança no sentido do convívio social humano e do respeito mútuo.

Hoje, esses dois conceitos são utilizados das mais variadas formas, alguns os consideram sinônimos, outros atestam que a diferença está no seu nível de abstração do real, sendo a ética uma reflexão e a moral um conjunto de regras concretas. Independente da definição, existe uma necessidade de desenvolvimento moral e de reflexão nas diversas etapas da vida. O presente estudo foi baseado em um conceito específico de moral que está atrelado a um sentimento de obrigatoriedade, e em um conceito de ética que inclui o projeto de vida pessoal e a própria moral para se ter uma vida boa. Esses conceitos são discutidos na obra Moral e Ética, Dimensões Intelectuais e Afetivas, de La Taille (2006).

Com os conceitos do autor e por meio de um questionário respondido pelos graduandos em Administração, procurou-se investigar a presença da reflexão ética e do desenvolvimento moral ao longo do curso, além de abranger como esse tipo de discussão teve lugar ao longo da graduação e, ainda, as perspectivas e necessidades dos alunos para esse tipo de aprendizado.

\section{Desenvolvimento}

Piaget (1994) propôs que, em paralelo ao desenvolvimento cognitivo, ocorria também um desenvolvimento moral na criança. O primeiro contato com as regras se dá por meio de uma autoridade, figura na qual a criança deposita confiança, amor 
ou medo; este momento é caracterizado pela heteronomia em que a regra é válida por si só. Quando a criança passa a entender os princípios e valores, ela constrói, por meio da cooperação, reflexões sobre as motivações da regra que transpassam a coação da autoridade, alcançando o estágio da autonomia (LA TAILLE, 2006).

Esse processo de construção moral sucede nos mais variados âmbitos da vida em sociedade, é sequencial e continua ocorrendo mesmo na fase adulta. Piaget (1994), por conta do próprio paralelo com o desenvolvimento cognitivo, afirma a necessidade da razão para que a moral se desenvolva, e, de fato, o filósofo Immanuel Kant (17241804) já apresentava a moral como uma máxima da própria razão (KANT, 2004).

La Taille (2006, p. 29) vai acrescentar a necessidade de sentimentos para o despertar dessa reflexão e desenvolvimento moral, e com isso ele passa a definir moral e ética a partir das perguntas "como devo agir?" e "que vida quero viver?", respectivamente. A pergunta moral, proposta pelo autor, tem um sentido de obrigatoriedade, remetendo a uma discussão sobre as regras, princípios, valores e ainda aos conteúdos claramente morais de justiça e generosidade. Já a pergunta-definição do conceito de ética não pode ser vista pela simples "vida boa" ou "de qualidade", ou seja, somente por prazeres e felicidade, a ela devem estar associados elementos psicológicos que permitam ao indivíduo de fato viver bem, e isso implica a necessidade de se seguirem a moral, suas regras, princípios e valores, pautados na justiça, na generosidade e por fim no autorrespeito, de forma que a pessoa moral respeite aquilo que ela acredita como correto ao realizar seu projeto de vida.

A ética engloba a moral. Contudo, ela contempla o projeto de vida, e um de seus âmbitos é a própria trajetória profissional; desse modo, entende-se a necessidade de uma reflexão moral e ética ao longo da graduação para que, na busca pelo sucesso profissional, os egressos da universidade consigam seus objetivos de forma moral, respeitando seus princípios e valores e alcançando uma vida boa que se balize no respeito ao próximo. A falta dessa reflexão pode levar a uma busca por sucesso que impede a percepção das consequências de determinadas ações, para com pessoas próximas ou distantes do indivíduo; é o chamado "sucesso a qualquer preço". Essa atitude eliminaria todo o respeito aos valores que deveriam direcionar as perspectivas éticas.

O professor, como apresentam Caetano e Silva (2009), tem papel fundamental na educação e formação de cidadãos, não só da perspectiva técnica e teórica de cada um dos cursos, mas também do ponto de vista humano e, dessa forma, moral e ético. Assim, a universidade se torna palco dessa discussão a fim de explorar a percepção dos próprios discentes quanto às discussões sobre o seu sucesso profissional, seu projeto de vida, e os cuidados quanto à percepção do respeito ao outro ao trilhar esse caminho.

Em específico, a graduação em Administração possui um interesse particular nessa área, pois os administradores têm uma relação com o outro por meio do trabalho ou até mesmo do dinheiro. Fica claro que na formação desse profissional essa discussão deve ser levada em conta e alinhada com o projeto de vida do aluno.

Para trabalhar tal assunto, foi aplicado um questionário semiaberto a catorze alunos do curso, o que permitiu ao respondente pensar e justificar a sua resposta: para cada uma das perguntas e subtópicos, era pedido que justificasse e elaborasse sua resposta. Tendo em mãos as respostas, procedeu-se à digitalização das informações e à análise das mesmas, a fim de se obter a impressão geral do grupo.

A primeira questão buscou informações sobre o projeto de vida do indivíduo, sua extensão em tempo, a inclusão da preocupação com o "outro" e as influências na sua formulação. Na sequência, investigaram-se as reflexões que partem da universidade sobre o sucesso profissional, como os alunos são incentivados a alcançarem o sucesso e qual a frequência dessa manifestação. Da mesma forma, a pergunta 3 explora os possíveis ônus do sucesso profissional, e em qual nível de proximidade eles incidem. Por fim, os respondentes puderam dar a sua opinião sobre essa reflexão no ambiente acadêmico (ver figura 1). 
Nome:

Curso:

Data de nascimento:

Semestre: Início do curso:

É sua primeira graduação?

Solicitamos que você responda as questões abaixo considerando a sua experiência acadêmica nesta universidade. Solicitamos ainda, que, ao fazê-lo você apresente a justificativa de suas respostas.

\section{Lembre-se de comentar todas as respostas de cada um dos itens e subitens.}

Em sua percepção:

1. Você tem, ainda que não redigido, um projeto de vida norteado pelo objetivo de uma vida boa ou de qualidade?

(se sim)

1.1. Este plano contempla realizações a curto (até um ano), médio ( 2 a 5 anos) e longo prazo (mais de 6 anos)?

1.2. Nesse projeto você identifica/contempla uma preocupação com o "outro"? Em que nível?

a. Nível imediato (família, grupos locais, comunidades, bairro)

b. Nível intermediário (cidade e região)

c. Nível intermediário avançado ( cidade, estado, país)

d. Nível avançado (outros países e povos)

1.3. Quais as influências, que você reconhece na proposição/organização de seu projeto de vida? (Ex: pessoas, espaços e outros).

2. A universidade apresenta informações e reflexões quanto ao sucesso profissional?

(se sim)

2.1. No discurso apresentado pela instituição, o que é "sucesso profissional"?

2.2. Os alunos são incentivados a conquistarem o sucesso profissional? Como isso é feito?

2.3. Quais são, caso ocorra, as orientações veiculadas pela universidade para que o sucesso profissional seja alcançado?

2.4. A frequência com que a universidade se manifesta quanto ao sucesso profissional é
a. Insuficiente
b. Suficiente
c. Intensa e expressiva.

3. A universidade apresenta informações e manifesta a preocupação quanto ao possível ônus que o sucesso profissional pode trazer para as demais pessoas?

3.1. Caso apresente, em que nível esta preocupação incide:
a. nível imediato (família, grupos locais, comunidades, bairro)
b. nível intermediário (cidade e região)
c. nível intermediário avançado (cidade, estado, país)
d. nível avançado (outros países e povos)

3.2. A frequência com que a universidade se manifesta em relação aos possíveis ônus do sucesso profissional é:
a. insuficiente
b. suficiente
c. intensa e expressiva

4. O sucesso profissional deve ser abordado no espaço universitário? Se sim, como você considera que a universidade deveria fazê-lo?

Figura 1 - Questionário com perguntas abertas. 


\section{Resultados}

Nesse primeiro grupo de questões, buscou-se identificar se os respondentes possuíam um projeto de vida norteado pela vida boa ou de qualidade. Se esse projeto apresentasse preocupações com o outro e encorpasse a moral, ele poderia ser chamado de projeto ético.

Quanto às considerações de projeto de vida, todos os catorze respondentes já estabeleceram uma trajetória.

Sim, um projeto de vida não redigido no qual pretendo ser bem-sucedida pessoal e profissionalmente, o qual muda com frequência. (P33) ${ }^{1}$

Eles buscam uma vida boa ou de qualidade; no entanto, alguns indivíduos se concentram somente em um ponto específico, como sucesso profissional:

Planejo concluir a graduação no tempo ideal e conseguir um estágio em alguma empresa, de preferência antes de eu me formar, para iniciar logo minha carreira profissional. Quanto antes eu começar minha carreira, antes irei alcançar um bom cargo que irá garantir uma vida boa. (P25)

É interessante que quatro indivíduos já descrevem, no projeto de vida, alguns objetivos pessoais e que levam a preocupação com o "outro".

[...] tudo o que é em excesso ou em falta prejudica algo, temos que dar a devida atenção para todas as áreas da vida e, principalmente, analisando e vivendo no amor entre as pessoas. (P27)

Vê-se que os respondentes conseguem identificar um projeto de vida que vai ao encontro do que se referiu anteriormente como vida boa ou de qualidade; muitos não apresentam um plano concreto, mas escolhem um caminho como a vida profissional para alcançar seus objetivos pessoais, trilhando uma trajetória que tenta, ainda que na incerteza dos acontecimentos futuros, responder à pergunta ética de La Taille (2006, p. 29): "Que vida quero viver?”.
Esse plano de vida poderia contemplar ações de curto, médio e longo prazo, sendo o curto prazo o período até um ano, o médio de dois a cinco anos, e o longo prazo mais de seis anos. Como os projetos de vida não são claramente definidos, espera-se que, quanto mais longe da atualidade, menos objetiva seja a realização.

Contempla realizações de curto e médio prazo, pois são os pontos onde ainda posso ter certo controle. (P31)

Contudo, alguns objetivos de longo prazo são pessoais e, portanto, bem-definidos. Por exemplo, planos como casamento, emprego almejado, negócio próprio:

Curto prazo: conseguir um estágio em uma grande empresa. Médio prazo: estar em um cargo maior e me casar. Longo prazo: Constituir uma família (filhos) e ajudar as pessoas mais necessitadas. (P19)

Mesmo com esses objetivos pontuais, a preocupação com o outro começa a se apresentar como uma parte do projeto de vida.

O plano de vida de longo prazo é a constituição de uma família e a realização de viagens nacionais e internacionais ainda com ações voluntárias e sociais. A longo prazo espero que minhas atitudes, que se iniciaram em nível imediato, alcancem um nível avançado. (P21)

Essa preocupação não existe em todas as pessoas: dez dos treze respondentes se atêm a coisas próximas e não envolvem um "outro" mais distante em sua vida. Existe a ideia de que o seu plano de vida não interfere em nível avançado (outros países e povos), somente se referindo aos níveis intermediário avançado (cidade, estado e país), intermediário (cidade e região) e imediato (família, grupos locais, comunidades e bairro).

[...] em nível imediato: pretendo construir uma família e poder ajudar as pessoas mais 
próximas da maneira que for possível. Muito pouco em nível intermediário: apenas em quesitos que acabam influenciando, como ser um bom cidadão. E em nível intermediário avançado e avançado praticamente não identifico. (P33)

A preocupação com o outro é presente nos planos dos três respondentes restantes; isso indica uma busca por evolução não só reflexiva, mas também de ações dentro dos níveis morais, que segundo Piaget (1994) e Kohlberg (1971) são mais avançados.

A preocupação com o outro é constante por estarmos rodeados e precisarmos dessas pessoas para qualquer ação direta ou indiretamente, então tento buscar sempre todos os níveis (imediato, intermediário, intermediário avançado e avançado), amar e respeitar quem não conhece é uma tarefa difícil, mas não impossível. (P27)

Quanto à existência de uma influência na construção do projeto de vida, são exemplos a família, a fé e a própria mídia.

Família. A família acaba influenciando nas escolhas das minhas decisões. Penso no julgamento que irão fazer, e, muitas vezes, meus projetos são afetados por pressão ou opiniões. (P37)

[...] talvez tenha me deixado influenciar pelo "glamour" do mundo empresarial criado pela mídia e me interesso quando tenho contato com as pessoas as quais vivem este estilo de vida [...]. (P30)

Interessante que um dos respondentes identifica a influência dessa autoridade, mas a questiona ironicamente:

Reconheço a influência de meu pai, que trabalhou muito para se estabelecer, e da sociedade em geral, que parece generalizar a trajetória de vida que as pessoas "devem" ter. (P26)

Como observaram La Taille (2006), Kohlberg (1971) e Piaget (1994), não se pode negar que essa influência seja um passo necessário do desenvolvimento; ela é saudável no sentido de aconselhamento. Existe uma identificação da influência como positiva no bojo da construção do projeto de vida, não como um determinismo autoritário, mas como uma ajuda ou uma inspiração. Dois relatos indicam a importância do que Piaget (1994) chamou de cooperação:

Reconheço influências de minha família e amigos, as coisas boas em que me espelho e as ruins que desejo não reproduzir em minha vida. Vejo também lugares (empresas, por exemplo) que seguem modelos que eu adoraria seguir e algumas pelas quais eu tenho certo repúdio e, também, não quero reproduzir. (P23)

Minha própria perspectiva de mundo e aspirações de futuro moldam meu projeto; porém, ocasionalmente procuro opiniões de outras pessoas para isto. (P20)

A análise do plano de vida dos respondentes conseguiu identificar que entre os alunos existe uma projeção futura que pode ou não estar associada ao "outro". Isso posto, o longo prazo tem foco nas realizações pessoais e não tanto na preocupação com o próximo. Quanto às influências na construção desse projeto de vida, oito respondentes parecem se sentir obrigados a seguir o modelo prioritariamente definido por figuras de autoridade, já os outros utilizam isso para criar o seu próprio trajeto.

A definição do plano de vida não basta para identificar o plano ético, a resposta a "Que vida quero viver?" deve, como apresenta La Taille (2006, p. 26), conter o plano moral, ou seja, a preocupação com o "outro". Dentre os participantes, a preocupação com o outro se atém às pessoas próximas, somente quatro projetos de vida abrangem indivíduos mais distantes.

Existe um consenso dos alunos sobre a presença do termo sucesso profissional e suas diferentes definições. A ideia geral é a de que os professores e os grupos de extensão oferecem 
algumas discussões sobre o sucesso profissional, contudo cabe ao aluno se engajar nessas discussões e refletir sobre o assunto.

Sim, vários professores já mencionaram e discutiram sobre o tema. (P24)

A Universidade propicia eventos e disciplinas que vão ao encontro da carreira de cada um, mas compete a cada aluno participar dos eventos que vão ao encontro das suas próprias proposições de sucesso profissional e pessoal. (P21)

Os respondentes também apontam o sucesso profissional como subjetivo, uma perspectiva similar à ideia de ética como plano de vida de La Taille (2006), e também fazem uma crítica à sua abordagem no ambiente universitário.

Uma pessoa pode considerar sucesso profissional ganhar muito dinheiro, outras acreditam que ter qualidade de vida e fazer o que gosta é alcançar o sucesso. (P30)

Alguns professores tentam fazer algumas discussões como essa, mas acredito que caberia ter mais, e a universidade acaba não dando informações ou reflexões sobre o assunto, deixando o aluno despreparado para o mercado de trabalho. Algumas vezes, o professor esbarra na barreira dos alunos que não se importam com nada e não prestam atenção, desmotivando o professor. Por outro lado, também existem aqueles professores e coordenadores que não se importam com o conteúdo passado aos estudantes, e só fazem o mínimo que se pede. (P37)

Fica claro que, no papel de formadora de profissionais de nível superior, a universidade é importante não só na educação para a área de atuação, mas implica também desenvolver reflexões quanto à ética e aos desdobramentos do sucesso profissional; vê-se que a necessidade de reflexão dos alunos não é atendida, apesar de percebida pontualmente por eles próprios.
Já a definição da universidade acerca do sucesso profissional, na visão dos alunos, vai ao encontro de uma carreira bem-sucedida.

Pelo que posso perceber, no discurso da universidade, "sucesso profissional" é você conseguir um emprego pelo qual estudou e ter um bom retorno financeiro. (P33)

Trabalhar numa boa posição, reconhecida pelo mercado. (P26)

Encontramos uma menção contundente quanto à ausência de reflexão moral no exposto da universidade sobre o sucesso profissional.

Os alunos são incentivados de forma a seguirem a filosofia da escola e não seus próprios valores, a meu ver é quase uma "lavagem cerebral", mas creio que a decisão de como fazê-lo ainda seja individual. (P23)

Ainda assim, são apresentados incentivos ao sucesso profissional de formas diferentes dentro da universidade, ou seja, o incentivo pode ocorrer por meio de grupos de extensão, palestras, professores e aulas.

Principalmente pelos professores, muitos transmitem isso por meio de serem rigorosos, e outros por meio de discursos para que sejamos bons alunos e, consequentemente, alcancemos o sucesso profissional. (P24)

Existe uma insatisfação quanto a essa abordagem de sucesso profissional e, com isso, uma consciência dos discentes de que esse sucesso é parte da ética e mais do que aquilo que lhes é apresentado.

Não consigo identificar orientações específcas neste sentido. Alguns professores utilizam o sucesso profissional como "desculpa" para dar alguns sermões, mas facilmente se percebe que aquela não é a real preocupação deles. (P33) 
A frequência com que a universidade se manifesta quanto ao sucesso profissional se apresentou em nove respostas como "insuficiente", em três como "suficiente", e uma "intensa e expressiva". Quando "intensa e expressiva", a resposta considerou o sucesso profissional como resultado do conhecimento e das experiências do aluno, oferecidos pela universidade.

É suficiente e intensa e expressiva, pois é visível a busca dos alunos por garantir esse sucesso, e a universidade sempre oferece essas oportunidades (estágios, intercâmbios e grupos de extensão). (P19)

Como suficiente, essa frequência foi dada pela percepção do aluno de que não é necessário trabalhar o tema dentro da universidade; e se insuficiente, os alunos demonstram uma insatisfação quanto à reflexão sobre o sucesso profissional.

Acho que é o suficiente. Não é bastante, mas penso que não é tão necessário tentar passar este conceito, visto que é consideravelmente subjetivo. (P20)

Eu diria que pouco efetiva, uma vez que a partir do momento que entramos no curso começa uma "propaganda" intensa e expressiva sobre o sucesso profissional, como devemos fazer para alcançá-lo e o que devemos evitar a qualquer custo, tudo isso de uma forma quase como um terrorismo. (P22)

Ao analisarmos as respostas quanto ao sucesso profissional e à visão da universidade, percebe-se que são contemplados a formação do aluno e seu sucesso que envolve dinheiro, fama, prestígio e o mercado de trabalho. As discussões no ambiente universitário, na opinião dos alunos, são raras ou superficiais e sempre devem ser buscadas pelo próprio aluno. $\mathrm{Na}$ concepção dos discentes, o sucesso profissional é mais do que aquele apresentado pela universidade.
Busca-se, por fim, entender se o ambiente universitário possui discussões sobre o ônus desse sucesso profissional, ou seja, a consequência dele para as outras pessoas. Será que essa discussão existe? Em qual nível de proximidade ela incide?

Quanto ao ônus desse sucesso, nove dos treze respondentes não percebem a presença desse tema por parte da universidade, os outros, quando percebem, a citam em momentos pontuais.

Insuficiente. A não ser, talvez, em alguma disciplina referente ao assunto, este "ônus" não é abordado no contexto universitário. (P33)

Não. Não percebo no espírito da universidade esse tipo de preocupação, pelo menos não nos profissionais com que tenho contato. Percebo que a universidade está mais preocupada em somente formar os alunos para o mercado de trabalho, sem pensar no que isso pode acarretar. (P37)

Com a inexistência dessa manifestação, percebe-se que o nível de preocupação também não chega a ser avançado (a outros países e povos), ficando então em nível imediato (família, grupos locais, comunidades e bairro) e intermediário (cidade e região).

A preocupação incide em nível intermediário, refletindo sobre os reflexos diretos da instalação de uma nova empresa, como exemplo. Mas não aborda os níveis avançados. (P32)

Um exemplo afirmativo sobre a ideia de que a manifestação da universidade sobre esse tema vai ao encontro do seu objetivo de formar estudantes, e não necessariamente de ajudá-los a construir seu objetivo de vida de maneira ética, se encontra abaixo:

[...] De nível intermediário vemos o discurso muito presente desde o primeiro dia de aula com as frases "a sociedade [...] paga a sua faculdade, isso aqui é dinheiro público" e "estamos investindo em vocês para formar os melhores 
profissionais, aqueles que o país precisa", ou até os discursos mais clichês como "vocês são o futuro da nação, vocês são o futuro da elite pensante de nosso país" [...] em nível avançado só vejo essa preocupação quando se toca no assunto de intercâmbio ou publicaçôes cientificas. (O grifo é nosso, $\mathrm{P} 22$ )

Ficou claro que os alunos consideram a discussão quanto ao ônus do sucesso profissional, por parte da universidade, insuficiente ou até mesmo inexistente. Contraposta a tal configuração encontra-se uma manifestação em prol dessa temática:

[...] acho que deveriam ser consideradas as diferentes personalidades e individualidades, os valores morais e éticos deveriam ser mais dialogados e também deveriam ser apresentados os prós e os contras, para que os alunos possam ter todas as informações e não façam suas escolhas de maneira precipitada. (P19)

É constatada uma preocupação com a subjetividade do tema, mas isso parece ser algo que remete a uma necessidade de reflexão dentro do ambiente universitário. Os respondentes também elencam formas com as quais o tema deveria ser abordado.

Penso que deve ser feita algumas vezes, porém de forma reflexiva, a fim de auxiliar os alunos a se esclarecerem sobre o tema e ajudá-los a buscarem o que estão dispostos. O ônus do sucesso profissional também poderia ser abordado de forma satisfatória com alguns exemplos de consequências que a busca pelo sucesso pode trazer. (P20)

A universidade deveria fazê-lo realizando feiras de carreiras, onde os profissionais relatam suas trajetórias e como é a vida no trabalho. (P26)

O tema deve ser abordado na universidade, tanto no ponto de conhecer melhor o mercado, quanto dentro das disciplinas como forma de reflexão para gerar alguns padrões. (P30)
Os alunos querem uma abordagem mais contundente da universidade sobre o sucesso profissional e seu ônus; no entanto, não há o entendimento de que essa reflexão, dentro de seu projeto de vida, o faz um projeto ético em busca da resposta para "Que vida quero viver?".

\section{Conclusões}

A pesquisa trouxe importantes contribuições ao informar que a universidade, como formadora de profissionais, conta com o conceito de sucesso profissional muito voltado para o êxito na educação técnica, o que tem impedido as discussões ou reflexões em um nível subjetivo que é demandado pelos alunos e auxiliaria na construção de um projeto de vida ético.

Em contrapartida, a busca de reflexões sobre as consequências do sucesso profissional não é tão procurada pelos alunos, a preocupação deles com a inclusão da moral em seu projeto de vida para torná-lo um projeto de vida ético não parece ser tão importante, até mesmo por conta de existirem influências externas na constituição desse projeto de vida. Os alunos acreditam ser relevante para a formação moral e ética a reflexão sobre os possíveis ônus do sucesso profissional. Palestras, eventos, grupos de discussão e aulas são mencionados como meios para esse tipo de reflexão e ficam como sugestões para que as Universidades incluam, em sua atividade pedagógica diária, reflexões para a formação moral e ética.

A partir das respostas ao questionário se teve uma impressão geral de que os alunos percebem que essa discussão não é um ponto focal dos interesses da Universidade, mas deveria ser. Nesse sentido, há uma demanda por parte dos alunos que não seria suprida por uma única disciplina, mas pela inserção da discussão sobre o ônus do sucesso profissional em todo o âmbito do curso: conversas, reflexões e atividades pedagógicas que trabalhem dilemas morais na aplicação do conhecimento técnico. Grupos de discussão, atividades extracurriculares e inclusive as relações entre professores e alunos também são formas de melhorar a formação moral e ética no ensino de graduação. 
Contudo, para que essa reflexão tenha efeitos práticos, é necessário um esforço da própria universidade, que é omissa na percepção dos alunos, em colocar essa formação como um de seus objetivos, auxiliando o professor no exercício de sua função e incentivando os alunos a participarem destas atividades.

É interessante notar que os alunos, com um projeto de vida que envolve a preocupação com o "outro", também são aqueles que entendem a importância dessa reflexão no meio acadêmico, considerando errada a imposição da definição de sucesso dada hoje pelo mercado; mas nem todos os alunos pensam dessa forma, o que também diminui a procura por reflexões que envolvem ética e moral. Esse tipo de reflexão valoriza o ensino na graduação, entendendo que o ensino superior tem sua função técnica, mas também possui uma função social na formação do senso crítico e na própria reflexão sobre o exercício profissional. O estudo limita-se à amostra de alunos de um único curso de Administração e indica uma necessidade de ampliação da pesquisa, que por ora tem como intenção realizar uma primeira investigação e indicar a necessidade de melhorar a formação ética e moral na graduação.

\section{Nota}

1 Os excertos são seguidos da letra $P$ (Participante) e do número do protocolo.

\section{Referências Bibliográficas}

CAETANO, Ana Paula \& SILVA, Maria de Lurdes. "Ética profissional e Formação de Professores". Súsifo. Revista de Ciências da Educaşão, vol. 8, 2009, pp. 49-60.

KANT, Immanuel. Crítica à Razão Prática. São Paulo: Edições e Publicações Brasil Editora S.A., 2004.

KOHLBERG, Lawrence. "Stages of Moral Development". Moral Education, vol. 1, 1971, pp. 23-92.

LA TAILlE, Yves de. Moral e Ética, Dimensões Intelectuais e Afetivas. Porto Alegre: Artmed, 2006.

PIAGET, Jean. O Juizo Moral na Criança. São Paulo: Summus, 1994.

Publicado em 12/06/2018. 